\title{
Tumor Necrosis Factor- $\alpha$ Receptor Expression Correlates With Mucosal Changes and Biofilm Presence in Chronic Rhinosinusitis With Nasal Polyposis
}

\author{
Tamás Karosi, MD, PhD; Péter Csomor, MSc; István Sziklai, MD, DSc
}

\begin{abstract}
Objectives/Hypothesis: Biofilms might play a potential role in the pathogenesis and high recurrence rate of chronic rhinosinusitis with nasal polyposis (CRSwNP). Biofilm persistence has been thought to correlate with epithelial damage, subepithelial inflammatory cell infiltration, and tumor necrosis factor- $\alpha$ receptor (TNFR) expression in CRSwNP.

Study Design: Case-control experimental study.

Methods: A total of 36 patients with CRSwNP undergoing endoscopic sinus surgery were analyzed. The negative control group consisted of eight patients undergoing septoplasty for nasal obstruction without CRSwNP. The nasal polyps and inferior turbinate mucosa samples applied as negative controls were processed by hematoxylin-eosin (HE) and Gram staining and TNFR-I and TNFR-II-specific immunofluorescent assay.

Results: Biofilm was detected in 29 of 36 patients with CRSwNP and in none of the eight negative controls. Staining by HE showed strong correlation with the results of Gram staining protocol. In the biofilm-positive cases, TNFR-I and TNFR-II displayed homogeneous pattern of significantly increased epithelial expression compared to the biofilm-negative nasal polyps. In cases of biofilm absence, the expression pattern of TNF- $\alpha$ receptors was characterized by increased TNFR-II-specific immunoreaction. It was found that biofilm detectability corresponded to the integrity of nasal epithelium and to the dominant inflammatory cell type of the subepithelial layer.

Conclusions: Persisting biofilms might increase the epithelial sensitivity against TNF- $\alpha$ that result in epithelium destruction. Coexistence of biofilms and increased TNFR expression might explain the inflammatory mucosal changes, functional disorders, and therapy resistance featuring CRSwNP.

Key Words: Biofilm, chronic rhinosinusitis, nasal polyps, tumor necrosis factor- $\alpha$ receptors.

Level of Evidence: $3 b$.
\end{abstract}

Laryngoscope, 000:000-000, 2012

\section{INTRODUCTION}

Chronic rhinosinusitis (CRS) is a common inflammatory disease characterized by various symptoms (nasal obstruction, olfactory dysfunction, nasal discharge, and tension pain) that persist over 12 weeks. ${ }^{1,2}$ Chronic rhinosinusitis with nasal polyposis (CRSwNP) is a separate diagnostic and therapeutic entity, although the etiopathomechanism is still uncertain. ${ }^{1,2}$ Several hypotheses have arisen as the explanation of the pathogenesis of CRS, which is currently considered as an immunological disease affected by multiple factors. ${ }^{3,4}$ These are immunological disorders, environmental factors, allergic rhinitis, bronchial asthma, aspirin intolerance, Staphylococcus superantigens, fungal infections, and the presence of different biofilms. ${ }^{2-5}$

From the Department of Otolaryngology and Head and Neck Surgery, University of Debrecen, Medical and Health Science Center, Debrecen, Hungary.

Editor's Note: This Manuscript was accepted for publication December 14, 2011.

The authors have no funding, financial relationships, or conflicts of interest to disclose.

Send correspondence to Tamás Karosi, MD, Department of Otolaryngology and Head and Neck Surgery, University of Debrecen, Medical and Health Science Center, Nagyerdei Krt. 98, Debrecen, H-4032 Hungary. E-mail: karositamas@gmail.com

DOI: 10.1002/lary.23190
Biofilms are the primary structures of bacterial and fungal survival and proliferation, which are characterized by a self-produced three-dimensional extracellular matrix that consists of polysaccharides, proteins, nucleic acids, and water. ${ }^{5-7}$ Bacterial biofilms are characterized by extremely high resistance against antibiotics and host immune reactions due to the physical barrier formed by the polysaccharide matrix that blocks the diffusion of antibiotics, superoxides, immunoglobulins, and opsonins. ${ }^{5-7}$ Biofilms might contribute to the epithelial damage and subsequent hyperplasia of the subepithelial layer infiltrated by inflammatory cells. ${ }^{8}$ Furthermore, persisting biofilms in CRSwNP cases may be responsible for surgical failures and high recurrence rate of disease. $^{1,4,5,7}$ Because biofilms are reported to play a central role in the pathogenesis of CRSwNP, a rapid, inexpensive, and reliable method was necessary for biofilm detection. ${ }^{5,9}$ In 2010, Hochstim et al. reported a reliable and robust method for biofilm detection that was based on conventional hematoxylin-eosin (HE) staining of fresh surgical specimens obtained from patients with CRSwNP. ${ }^{10}$ In 2011, Tóth et al. confirmed these results by the combined application of $\mathrm{HE}$ and Gram staining protocols. ${ }^{11}$

Several cytokines (interleukin [IL]-1, IL-4, IL-5, IL-6, IL-8, and tumor necrosis factor- $\alpha[\mathrm{TNF}-\alpha]$ ) might 
play important roles in the olfactory dysfunction, which is a common and debilitating symptom of patients with CRSwNP. ${ }^{12-14}$ The epithelial damage, desensitization of odorant-induced signaling, and apoptotic loss of olfactory neurons are mainly associated with increased TNF- $\alpha$ production in the subepithelial layer of nasal polyps. ${ }^{12,13}$ Furthermore, TNF- $\alpha$ inhibits the regeneration of immature olfactory neurons from their progenitor cells located in the basal layer of the olfactory epithelium. ${ }^{12,13}$ However, the mechanism of olfactory dysfunction in CRSwNP is not completely understood. ${ }^{12,13}$ TNF- $\alpha$ can also have adverse effects on the respiratory mucosa, causing ciliated cell loss, epithelial metaplasia, and further accumulation of inflammatory cells in the subepithelial layer. ${ }^{8,14}$ The association between biofilm presence and proinflammatory cytokine expression, however, is not clear. ${ }^{15}$

Biological effects of TNF- $\alpha$ are mediated by two different receptors. ${ }^{16,17}$ Type I TNF- $\alpha$ receptor (TNFR-I), a member of TNF superfamily I, is generally expressed by all nucleated human cells and has a broader spectrum of biological influences than type II TNF- $\alpha$ receptor (TNFRII). ${ }^{18,19}$ TNFR-II, a member of TNF superfamily II, is exclusively expressed by lymphocytes and antigen presenting cells. ${ }^{16,18}$ Increased expression of TNFR-II is usually seen in acute inflammatory reaction, because it plays an important role in the recruitment of T-helper cells via induction of proinflammatory cytokine release (IL-1, IL-4, IL-5, IL-6, and TGF- $\beta$ ). ${ }^{17,18}$ Activated TNFR-I forms a homotrimer structure activating the silencer of death domains, which binds the TNFR-associated death domain, allowing three different ways of signal transduction. ${ }^{20}$ The first and most important way is the activation of the nuclear factor kappa-light-chain-enhancer of activated $B$ cells system providing inflammatory cell survival and proliferation. ${ }^{20,21}$ The second way is the activation of the mitogen-activated protein kinases (MAPK) system, which is associated with the phosphorylation of several transcription factors (c-Jun N-terminal kinase, p38MAPK, extracellular signal-regulated kinases) leading to intense inflammatory cell proliferation. ${ }^{20,21}$ The third way of TNFR-I-associated signalization is the death domain-mediated and caspase-associated induction of apoptosis. $^{20,22}$

This study investigated the presence of biofilms on the surface of nasal polyps corresponding to the subepithelial inflammatory changes and epithelial TNF- $\alpha$ receptor expression.

\section{MATERIALS AND METHODS}

\section{Patients and Controls}

A case-control experimental study was performed on nasal polyp specimens obtained from patients with CRSwNP who underwent endoscopic sinus surgery (ESS) in the Department of Otorhinolaryngology and Head and Neck Surgery, University of Debrecen. Nasal polyps were collected between February 2010 and July 2010. The group of 36 patients consisted of 21 men and 15 women (mean age, 46.7 years; range, $27-71$ years) with the diagnosis of CRSwNP confirmed by nasal endoscopy and computed tomography (CT) scans of paranasal sinuses. The Lund-Mackay scores of coronal reconstructed CT scans varied
TABLE I.

Clinically Relevant Data of Patients With Chronic Rhinosinusitis With Nasal Polyposis

\begin{tabular}{lc}
\hline Characteristic & Value \\
\hline No. of patients & 36 \\
Gender ratio (F/M) & $0.71(15 / 21)$ \\
Average age (range), yr & $46.7(27-71)$ \\
Bronchial asthma, no. (\%) & $5(13)$ \\
Allergic rhinitis, no. (\%) & $3(8)$ \\
Aspirin intolerance, no. (\%) & $1(3)$ \\
Average Lund-Mackay score (range) & $20(9-24)$ \\
Previous ESS, no. (\%) & $8(22)$ \\
Topical steroid treatment, no. (\%) & $36(100)$ \\
Systemic antibiotic treatment, no. (\%) & $2(5)$ \\
\hline \hline
\end{tabular}

$\mathrm{F} / \mathrm{M}$ = female/male; ESS = endoscopic sinus surgery.

between 9 and 24, with an average score of 20 indicating serious involvement of paranasal sinuses by CRS. The score was higher than 20 in $80 \%$ of patients $(n=29)$. The clinical history and findings of physical examinations were obtained during confirmation of the diagnosis of CRSwNP. Clinical information on bronchial asthma, allergic rhinitis, aspirin intolerance, previous ESS, topical steroid treatment, and systemic antimicrobial therapy was recorded before surgery. Five patients $(13 \%)$ had bronchial asthma, $8 \%(\mathrm{n}=3)$ had allergic rhinitis, and $3 \%(\mathrm{n}=$ 1) had the diagnosis of aspirin intolerance. This patient had complete acetylsalicylic acid triad (aka, Samter's triad: nasal polyposis, bronchial asthma, and aspirin intolerance). ${ }^{1,2}$ Diagnosis of allergic rhinitis was based on the clinical history, physical examination, and allergen-specific intracutaneous skin-prick test. In some cases, inhalation allergen-specific serum immunoglobulin G (IgG) levels were also measured by enzyme-linked immunosorbent assay. The diagnosis of bronchial asthma was based on the clinical history and on the respiratory functional test. The diagnosis was stated by a pulmonologist in all cases. Aspirin intolerance was based on the presence of aspirininduced hypersensitive reaction in the clinical history of the patients. Repeated ESS was performed in $22 \%(\mathrm{n}=8)$ of patients, which is an important predictive factor for CRS recurrence. In this group, the number of previous surgeries varied between one and six, with an average ESS number of 2.3. All patients were treated by topical mometasone furoate monohydrate (Nasonex; Merck/Schering-Plough, North Wales, PA), $200 \mu \mathrm{g} /$ day before surgery. The average period of intranasal steroid treatment was 27.3 months, which varied between 5 and 57 months. Preoperative systemic antibiotic treatment was performed in two $(5 \%)$ patients due to recurring acute rhinosinusitis. Table I summarizes the clinical history of patients with CRSwNP.

All the nasal polyps collected during ESS were processed by histopathological analysis. Only nasal polyps larger than 2 $\mathrm{cm}$ and could be removed by a straight ESS forceps without any surface injury or iatrogenic disruption of biofilm layers were analyzed. The removal was gently performed at the roots of the nasal polyps.

Eight patients (males $=7$; females $=1$; mean age, 41.3 years; range, 22-57 years) scheduled for septoplasty for nasal obstruction without a medical history of CRS were recruited into the negative control group. Tissue specimens of approximately $0.2 \mathrm{~cm}^{3}$ were obtained from the anterior mucosal surface of the inferior turbinate. All patients gave their informed consent before donating their tissue samples for the study. The 

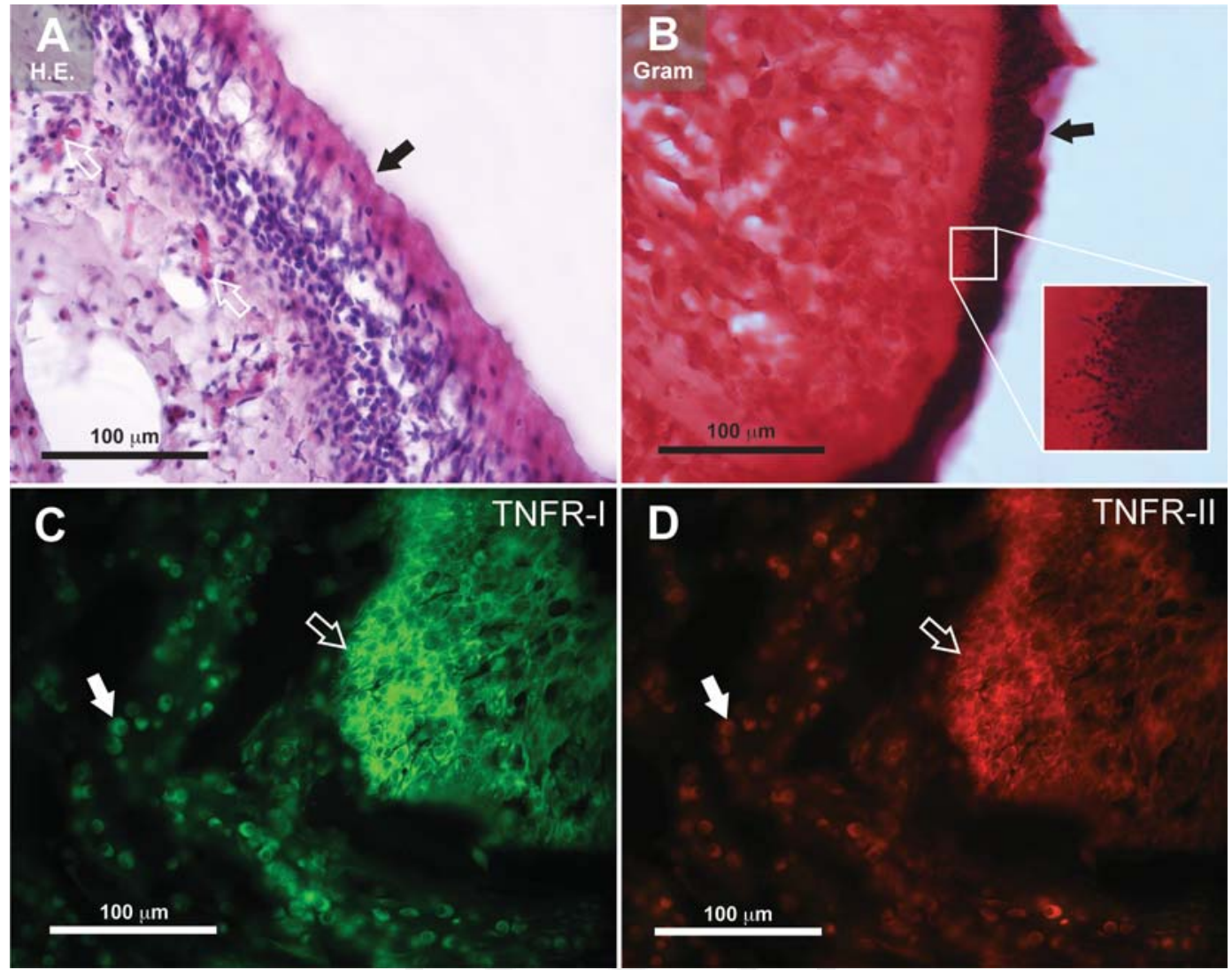

Fig. 1. Histopathological examination of a chronic rhinosinusitis with nasal polyposis specimen. (A) The respiratory epithelium shows a squamous cell metaplasia. A bulky and continuous biofilm layer can be identified on the surface of the epithelial layer (black arrow). The subepithelial layer is predominantly infiltrated by eosinophil granulocytes (empty arrows). (B) Gram staining indicates a bacterial biofilm consisted of Gram-positive cocci (small insert). (C) The epithelial layer represents intense tumor necrosis factor- $\alpha$ receptor (TNFR)-I-specific immunoreaction (empty arrow). Mononuclear cells and plasmacytes show strong cytoplasmic immunostaining for TNFR-I (white arrow). (D) Immunofluorescent assay for TNFR-II exhibits the same expression pattern. Empty and white arrows indicate identical structures of the previous section. H.E. = hematoxylin-eosin.

institutional ethical committee approved our study. The study was carried out according to the Declaration of Helsinki.

\section{HE and Gram Staining}

A combination of $\mathrm{HE}$ and Gram staining protocols is a reliable method for the detection of biofilm presence and corresponding histopathological changes, because HE staining is for the investigation of microscopic architecture, whereas the Gram protocol stains various microbiological elements. ${ }^{11}$ A total of 44 nasal mucosa specimens were fixed in $10 \% \mathrm{w} / \mathrm{v}$ formaldehyde. Specimens were embedded in $15 \%(\mathrm{w} / \mathrm{v})$ purified gelatin for 24 hours at $56^{\circ} \mathrm{C}$ and refixed in $4 \%(\mathrm{w} / \mathrm{v})$ paraformaldehyde for 24 hours at $20^{\circ} \mathrm{C}$. Blocks were cryoprotected in $20 \%$ (w/v) sucrose solution for 2 hours at $4^{\circ} \mathrm{C}$ and sectioned into 5 - $\mu \mathrm{m}$ slides at $-25^{\circ} \mathrm{C}$ (MNT-200; Slee, Mainz, Germany). Slides were stored in $0.1 \mathrm{M}$ phosphate-buffered saline (PBS) containing $0.03 \%(\mathrm{w} / \mathrm{v})$ sodium azide at $4^{\circ} \mathrm{C}$. Three consecutive 5 - $\mu \mathrm{m}$ frozen cut sections were examined as follows: 1) conventional staining with $\mathrm{HE}, 2$ ) conventional Gram staining, and 3) TNFR-I- and TNFR-II-specific immunofluorescent assays (IFA). Histological pretreatment protocol was performed by an independent laboratory assistant. Histological examinations were blinded for two independent researchers; one researcher analyzed the sections stained by $\mathrm{HE}$ and Gram (P.C.), and the other examined the results of IFA (т.к.). The criteria for the histological detection of biofilms were based on the presence of characteristic polysaccharide layer with Gram-positive or Gram-negative microcolonies. The architecture of epithelium and the subepithelial cellular infiltration were correlated to the presence or absence of biofilms and to the expression pattern of type I and II TNF- $\alpha$ receptors.

\section{TNFR-I- and TNFR-II-Specific IFA}

The third sections were washed for 20 minutes at $20^{\circ} \mathrm{C}$ in 0.2 M PBS containing protein block solution $(1 \%[\mathrm{w} / \mathrm{v}]$, bovine serum albumin, $0.09 \%[\mathrm{w} / \mathrm{v}]$, sodium azide, $0.1 \%[\mathrm{w} / \mathrm{v}]$, Tween20) (BioGenex, San Ramon, CA). Blocked sections were incubated with $0.005 \mathrm{mg} / \mathrm{mL}$ polyclonal goat anti-human TNF RI/TNFRSF1A antibody solution $\left(100 \mathrm{~mL}, 20^{\circ} \mathrm{C}\right.$, for 24 hours, continuous shaking) (R\&D Systems, Minneapolis, MN). The first primary antibody was washed with $0.2 \mathrm{M}$ PBS. Sections were incubated with $0.02 \mathrm{mg} / \mathrm{mL}$ monoclonal mouse hybridoma anti-human TNF RII/TNFRSF1B antibody solution $(100 \mathrm{~mL}$, $20^{\circ} \mathrm{C}$, for 24 hours, continuous shaking) (R\&D Systems). The second primary antibody was washed with $0.2 \mathrm{M}$ PBS. Sections were incubated with $0.005 \mathrm{mg} / \mathrm{mL}$ Northern Lights donkey anti-goat IgG labeled by NL-493 fluorochrome $\left(50 \mathrm{~mL}, 20^{\circ} \mathrm{C}\right.$, for 12 hours, continuous shaking) (R\&D Systems). The first secondary antibody was washed with $0.2 \mathrm{M}$ PBS. Sections were incubated with the second secondary antibody: $0.005 \mathrm{mg} / \mathrm{mL}$ Northern Lights donkey anti-mouse IgG labeled by NL-637 
TABLE II.

Histopathological Characteristics of Epithelial and Stromal Layers of Nasal Polyps Depending on Biofilm Presence.

\begin{tabular}{|c|c|c|}
\hline & \multicolumn{2}{|c|}{ Nasal Polyps-CRS Specimens (HE and Gram Staining, N = 36) } \\
\hline & Biofilm Positive ( $n=29,80.5 \%$ ) & Biofilm Negative ( $\mathrm{n}=7,19.5 \%$ ) \\
\hline Epithelium & $\begin{array}{l}\text { Fragmented columnar epithelium without ciliated cells }(n=17) \text {, } \\
\quad \text { squamous cell metaplasia }(n=12)\end{array}$ & Ciliated columnar epithelium $(n=7)$ \\
\hline Subepithelial layer & $\begin{array}{l}\text { Eosinophil dominancy }(n=2) \text {, neutrophil dominancy }(n=24) \text {, } \\
\text { plasmacyte dominancy }(n=3)\end{array}$ & $\begin{array}{l}\text { Eosinophil dominancy }(\mathrm{n}=5) \\
\text { neutrophil dominancy }(\mathrm{n}=0), \\
\text { plasmacyte dominancy }(\mathrm{n}=2)\end{array}$ \\
\hline
\end{tabular}

$\mathrm{HE}=$ hematoxylin-eosin.

fluorochrome $\left(50 \mathrm{~mL}, 20^{\circ} \mathrm{C}\right.$, for 12 hours, continuous shaking) (R\&D Systems). All antibody incubations were performed in a sterile humid chamber. Slides were covered by ultraviolet (UV) transparent mounting medium (PromoFluor Antifade Reagent; Promocell, Heidelberg, Germany). Imaging was performed under UV light with $510 \mathrm{~nm}$ wavelengths for NL-493 and 650 $\mathrm{nm}$ for NL-637 fluorochrome with 96 to $123 \mathrm{~ms}$ exposure time. Photographs were archived in jpeg file format (Axioskop2 MOT, Axiovision 4.0; Zeiss, Oberkochen, Germany). Average cell counts with detectable TNFR-I and II expression were measured in a $200 \mathrm{~mm} \times 200 \mathrm{~mm}$ centrally focused area of the epithelial layer. Statistical analysis was performed by MannWhitney $U$ test with a $95 \%$ confidence interval using SPSS version 9.0 for Windows (SPSS, Inc. Chicago, IL)

\section{RESULTS}

Altogether, 36 patients with CRSwNP who underwent ESS were included in this study. The histopathological examination revealed inflammatory nasal polyps with eosinophilic, polymorphonuclear, and plasmacyte infiltration of the subepithelial layer in all cases. Bacterial $(\mathrm{n}=21)$, fungal $(\mathrm{n}=4)$, or combined $(\mathrm{n}=4)$ biofilms were detected in $29(80.5 \%)$ of 36 patients with CRSwNP (Fig. 1, Table II). In the biofilmnegative cases $(\mathrm{n}=7,19.5 \%)$, histopathological analysis revealed ciliated columnar epithelium with predominantly eosinophilic infiltration of the subepithelial layer (Fig. 2, Table II). All patients diagnosed with allergic
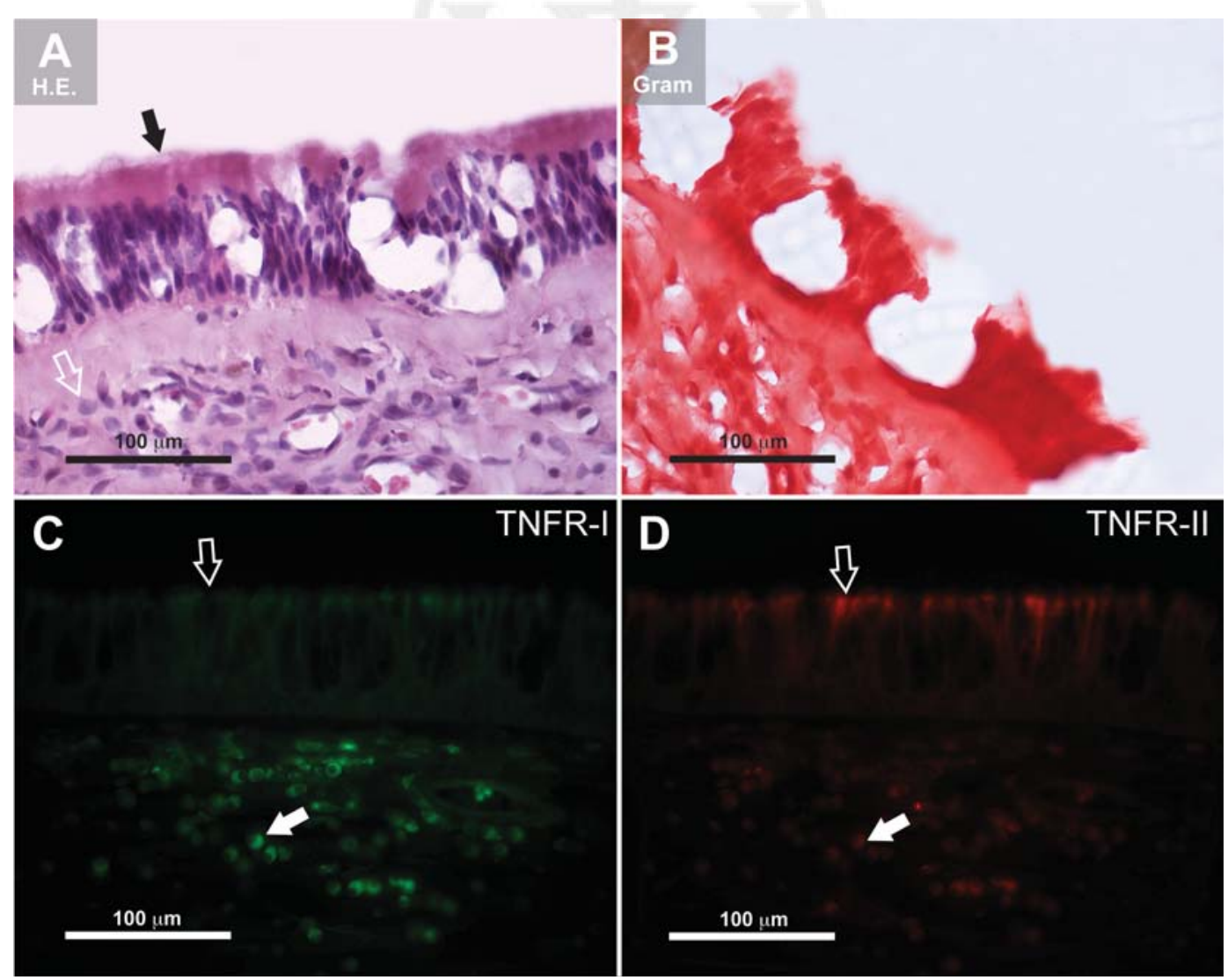

Fig. 2. Histopathological analysis of a chronic rhinosinusitis with nasal polyposis specimen. (A) Disorganized columnar epithelium and empty foamy cells can be detected (black arrow). Basal lamina is a well-identified structure. The subepithelial layer is infiltrated by plasmacytes (empty arrow). (B) Biofilm structures cannot be detected on the surface of nasal epithelium. (C) Tumor necrosis factor- $\alpha$ receptor (TNFR)-I-specific immunostaining is practically negative for epithelial cells (empty arrow). In contrast, subepithelial mononuclear cells show intense immunoreaction (white arrow). (D) The apical part of the epithelial cells represents a considerable TNFR-II-specific immunoreaction (empty arrow). Empty and white arrows indicate identical structures of the previous section. H.E. = hematoxylin-eosin. 




Fig. 3. Average number of tumor necrosis factor- $\alpha$ receptor (TNFR)-I- and TNFR-II-positive epithelial cells in negative controls and in nasal polyps correlated to biofilm presence. The error bars indicate standard error of mean. ${ }^{*}$ Cell counts were measured in a $200 \mathrm{~mm} \times 200 \mathrm{~mm}$ centrally focused area of the epithelial layer.

rhinitis ( $\mathrm{n}=3,42.8 \%$ ) were recruited into the biofilm negative group $(\mathrm{n}=7)$ (Table II). In our series, HE staining displayed a strong correlation with the results of Gram staining and was found to be a reliable predictor of the presence or absence of biofilms. No discrepancies were found between the two staining protocols (Table II). Disintegration or squamous cell metaplasia of the epithelial layer due to the subepithelial inflammatory reactions were strong predictors for biofilm detection (Fig. 1, Table II). Among biofilm-positive cases, neutrophil infiltration of the subepithelial layer was found to be the most important factor of biofilm presence (Fig. 1, Table II). In the biofilm-positive specimens, histopathological characteristics of the respiratory mucosa and the dominant inflammatory cell type of the subepithelial layer were strongly associated with the increased TNFR-I and II expression (Fig. 1). There was no statistically significant difference between the number of TNFR-I and II expressing cells (Fig. 3). It was found that normal respiratory mucosa with columnar ciliated epithelium is not associated with the presence of different types of biofilms (Fig. 2, Table II). Furthermore, predominant eosinophil infiltration of the subepithelial layer decreased the chance of biofilm detection (Fig. 2, Table II). According to IFA results, biofilmnegative cases were characterized by significantly decreased TNFR-I and II expression compared to biofilm-positive specimens $(P<.001)$ (Fig. 3). It was shown that the average number of TNFR-II-positive epithelial cells was significantly higher than the TNFR-I expressing population $(P<.05)$ (Fig. 3). No biofilm-like structures were detected in mucosal specimens obtained from the inferior turbinate of patients $(n=8)$ applied as negative controls (Fig. 4). In negative controls, the TNFR-I and II expressing cells were significantly underrepresented in the epithelial layer of the nasal mucosa (Fig. 4).

\section{DISCUSSION}

In the present study, we demonstrated the presence of biofilms in 29 patients with CRSwNP by the combined application of $\mathrm{HE}$ and Gram protocols. Absence of biofilms was not associated with the single employment of HE or Gram staining. Furthermore, biofilm detection showed statistically significant correlation to the increased TNFR-I and II expression in the epithelial layer of nasal polyps. Although the presence of biofilm itself is supposed to be one of the most important factors in the pathogenesis of CRSwNP, microbiological identification of different bacterial and fungal species involved in biofilm formation still requires culturing or fluorescence in situ hybridization analysis with species-specific oligonucleotide probes. ${ }^{5,9,10}$

There is increasing evidence that biofilms affect the intensity of subepithelial inflammatory reaction in CRSwNP. ${ }^{4,15}$ Plasmacytes, neutrophil and eosinophil granulocytes accumulating in the subepithelial layer of nasal polyps are responsible for the uncontrolled release of several proinflammatory cytokines., ${ }^{3,14}$ Increased expression of these peptides-mainly TNF- $\alpha$ - has serious morphological and functional consequences affecting the integrity of respiratory and olfactory mucosa. ${ }^{3,12,13}$

In general, cytokines produced by T-helper cells such as IL-4 and IL-5 are overexpressed in CRSwNP. ${ }^{3,14}$ It has been reported that single nucleotide polymorphism (SNP) of IL-4 promoter region is associated with nasal polyps, and IL-4 appears to modify the metabolic activity of fibroblasts. ${ }^{3,23}$ Enterotoxin B of Staphylococcus species induces IL-5 release in the subepithelial layer, whereas IL-8 seems to be upregulated by Staphylococcus epidermidis. ${ }^{3,24,25}$ Both cytokines are supposed to increase the subepithelial matrix production in nasal polyps. $^{3,24}$ IL-1 and TNF- $\alpha$ being proinflammatory cytokines are upregulated in CRSwNP, which can be associated with several disease-specific SNPs previously identified. $^{26}$ B-cell activating factor has been also reported to contribute to the pathogenesis of CRSwNP via the local induction of immunoglobulin A production and activation of eosinophil granulocytes. ${ }^{27}$ In contrast, cytokines having immunomodulator effects such as interferon- $\gamma$ and transforming growth factor- $\beta$ are downregulated in nasal polyps. ${ }^{3}$

In spite of the intense research, the mechanism of olfactory dysfunction and architectural changes of the nasal mucosa remains poorly understood in CRSwNP. ${ }^{12,13}$ TNF- $\alpha$ has been suggested to play a crucial role in olfactory dysfunction by the suppression of progenitor cell proliferation and olfactory regeneartion. ${ }^{13}$ In the transgenic mouse model for CRS, electro-olfactography results implied that TNF- $\alpha$ directly lead to olfactory neuron dysfunction that was independent from the severity of inflammatory reactions. ${ }^{13}$ This inflammatory process 


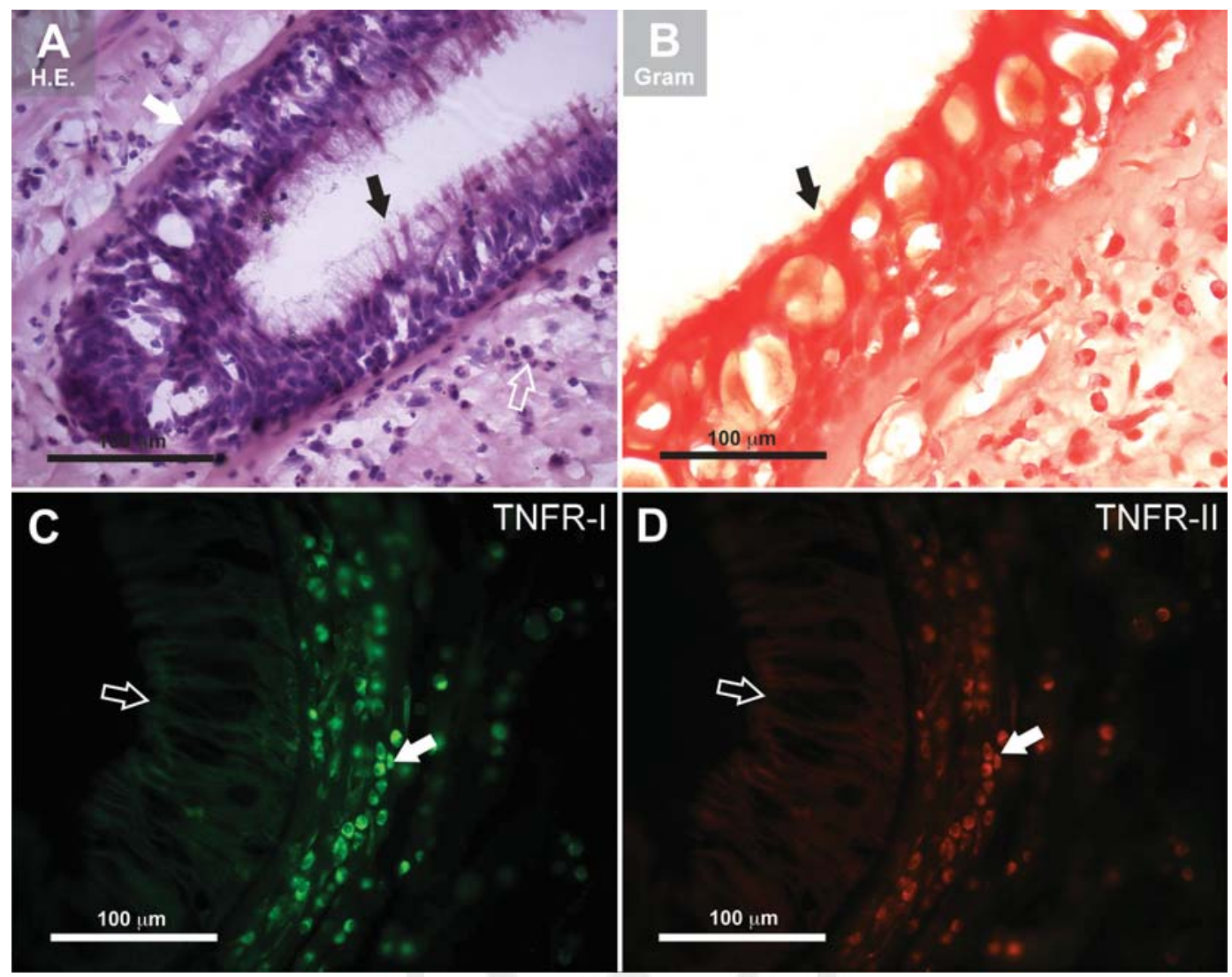

Fig. 4. Histopathological representation of a normal nasal mucosa specimen obtained from the inferior turbinate. (A) At high magnification, an intact ciliated columnar epithelium (black arrow) and a well-defined basal lamina (white arrow) can be detected. The subepithelial layer represents heterogeneous populations of plasmacytes, neutrophils, and eosinophils (empty arrow). (B) Biofilm cannot be detected on the surface of the epithelial layer (black arrow). (C) The ciliated columnar cells represents weak, almost negative, immunostaining for type I tumor necrosis factor- $\alpha$ receptors (TNFR-I) (empty arrow). Mononuclear cells and plasmacytes show a considerable positivity for TNFR-I (white arrow). (D) TNFR-II displays a quite similar expression pattern. Empty and white arrows indicate identical structures of the previous section. H.E. = hematoxylin-eosin.

seems to be reversible, because $\mathrm{TNF}-\alpha$ does not directly cause neuronal apoptosis. ${ }^{12,13}$ It has been reported that intranasal and oral administration of steroids (prednisolone, mometasone furoat) significantly decreases the expression levels of IL-1, Il- 6 and TNF- $\alpha$ in nasal polyps. ${ }^{14,24}$ These findings also support the hypothesis that the inflammatory reactions in CRSwNP are correlated to the elevated levels of proinflammatory cytokines. ${ }^{3,14,24}$

Corticosteroids have beneficial effects on the symptoms of CRSwNP and significantly decrease nasal obstruction and olfactory dysfunction. 1,2,14,15 Hypothetically, steroid treatment may have adverse effects on the biofilm presence and thickness via the inhibition of local immune response. ${ }^{11}$ As we have concluded previously, steroid and systemic antibiotic treatment might have a severe influence on the flora of nasal mucosa, and in fact these medications might affect the structure and thickness of biofilms. ${ }^{11}$ Because our patients were all treated by topical steroids, this association seems to be strong. In contrast, $43 \%$ of biofilm-negative specimens were obtained from patients with allergic rhinitis who were regular topical-steroid users. Furthermore, allergic rhinitis is not a real risk factor for CRSwNP by the current rhinologic consensus. ${ }^{1,2}$ In the future, placebo- controlled, double-blinded, dynamic studies will be necessary to prove this causative relation and to resolve this conflict.

\section{CONCLUSION}

The results of this study indicate an association between biofilm presence and increased expression of TNF- $\alpha$ receptors in CRSwNP. According to our observations, the severity of CRSwNP is associated with increased TNF- $\alpha$ receptor expression and consecutive epithelial damage, which is more likely to become colonized with bacteria. Although specific treatments are not yet available to target biofilm, its detection is an important requirement, because it is strongly associated with treatment failures and persistent symptoms of CRSwNP. ${ }^{1,2,10,11,28}$ In general, therapeutic considerations can be divided into two main groups: blockade of biofilm formation and eradication of biofilms that have already formed. ${ }^{28}$ Furthermore, an understanding of the role of TNF- $\alpha$ and its receptors in biofilm-positive CRSwNP cases may suggest novel therapeutic strategies for CRSassociated symptoms in the future. Further examinations are required to clarify the etiologic role of biofilms in the pathogenesis of CRSwNP. 


\section{BIBLIOGRAPHY}

1. Meltzer EO, Hamilos DL. Rhinosinusitis diagnosis and management for the clinician: a synopsis of recent consensus guidelines. Mayo Clin Proc 2011;86:427-443.

2. Marple BF, Stankiewicz JA, Baroody FM, et al.; American Academy of Otolaryngic Allergy Working Group on Chronic Rhinosinusitis. Diagnosis and management of chronic rhinosinusitis in adults. Postgrad Med 2009;121:121-139.

3. Otto BA, Wenzel SE. The role of cytokines in chronic rhinosinusitis with nasal polyps. Curr Opin Otolaryngol Head Neck Surg 2008;16:270-274.

4. Al-Mutairi D, Kilty SJ. Bacterial biofilms and the pathophysiology of chronic rhinosinusitis. Curr Opin Allergy Clin Immunol 2011:11:18-23.

5. Ferguson BJ, Stolz DB. Demonstration of biofilm in human bacterial chronic rhinosinusitis. Am J Rhinol 2005;19:452-457.

6. Mladina R, Poje G, Vukovic K, Ristic M, Music S. Biofilm in nasal polyps. Rhinology 2008;46:302-307.

7. Zernotti ME, Angel Villegas N, Roques Revol M, et al. Evidence of bacterial biofilms in nasal polyposis. J Investig Allergol Clin Immunol 2010; 5:380-385.

8. Galli J, Calo L, Ardito F, et al. Damage to ciliated epithelium in chronic rhinosinusitis: what is the role of bacterial biofilms? Ann Otol Rhinol Laryngol 2008;117:902-908.

9. Psaltis AJ, Ha KR, Beule AG, Tan LW, Wormald PJ. Confocal scanning laser microscopy evidence of biofilms in patients with chronic rhinosinusitis. Laryngoscope 2007;117:1302-1306.

10. Hochstim CJ, Choi JY, Lowe D, Masood R, Rice DH. Biofilm detection with hematoxylin-eosin staining. Arch Otolaryngol Head Neck Surg 2010;136:453-456.

11. Toth L, Csomor P, Sziklai I, Karosi T. Biofilm detection in chronic rhinosinusitis by combined application of hematoxylin-eosin and gram staining. Eur Arch Otorhinolaryngol 2011;268:1455-1462.

12. Sultan B, May LA, Lane AP. The role of TNF- $\alpha$ in inflammatory olfactory loss. Laryngoscope 2011;121:2481-2486.

13. Turner JH, Liang KL, May L, Lane AP. Tumor necrosis factor alpha inhibits olfactory regeneration in a transgenic model of chronic rhinosinusitis-associated olfactory loss. Am J Rhinol Allergy 2010;24:336-340.

14. Lennard CM, Mann EA, Sun LL, Chang AS, Bolger WE. Interleukin-1 beta, interleukin-5, interleukin-6, interleukin-8, and tumor necrosis factor-alpha in chronic sinusitis: response to systemic corticosteroids. Am J Rhinol 2000;14:367-373.
15. Hekiert AM, Kofonow JM, Doghramji L, et al. Biofilms correlate with TH1 inflammation in the sinonasal tissue of patients with chronic rhinosinusitis. Otolaryngol Head Neck Surg 2009;141:448-453.

16. Bazan JF. Emerging families of cytokines and receptors. Curr Biol 1993;3: 603-606.

17. Locksley RM, Killeen N, Lenardo MJ. The TNF and TNF receptor superfamilies: integrating mammalian biology. Cell 2001;104:487-501.

18. Wajant H, Pfizenmaier K, Scheurich P. Tumor necrosis factor signaling. Cell Death Differ 2003;10:45-65.

19. Grell M, Wajant H, Zimmermann G, Scheurich P. The type 1 receptor (CD120a) is the high-affinity receptor for soluble tumor necrosis factor. Proc Natl Acad Sci USA 1998;95:570-575.

20. Chen G, Goeddel DV. TNF-R1 signaling: a beautiful pathway. Science 2002;296:1634-1635.

21. Kriegler M, Perez C, DeFay K, Albert I, Lu SD. A novel form of TNF/cachectin is a cell surface cytotoxic transmembrane protein: ramifications for the complex physiology of TNF. Cell 1988;53: $45-53$.

22. Schulze-Osthoff K, Ferrari D, Los M, Wesselborg S, Peter ME. Apoptosis signaling by death receptors. Eur J Biochem 1998;254:439-459.

23. Yea SS, Yang YI, Park SK, et al. Interleukin-4 C-590T polymorphism is associated with protection against nasal polyps in a Korean population. Am J Rhinol 2006;20:550-553.

24. Bobic S, van Drunen CM, Callebaut I, et al. Dexamethasone-induced apoptosis of freshly isolated human nasal epithelial cells concomitant with abrogation of IL-8 production. Rhinology 2010;48: 401-407.

25. Yamamoto M, Kiyono H, Kweon MN, et al.. Enterotoxin adjuvants have direct effects on $\mathrm{T}$ cells and antigen-presenting cells that result in either interleukin-4-dependent or -independent immune responses. $J$ Infect Dis 2000;182:180-190.

26. Mfuna Endam L, Cormier C, Bosse Y, Filali-Mouhim A, Desrosiers M. Association of IL1A, IL1B, and TNF gene polymorphisms with chronic rhinosinusitis with and without nasal polyposis: a replication study. Arch Otolaryngol Head Neck Surg 2010;136:187-192.

27. Kato A, Peters A, Suh L, et al. Evidence of a role for B cell-activating factor of the TNF family in the pathogenesis of chronic rhinosinusitis with nasal polyps. J Allergy Clin Immunol 2008;121:1385-1392.

28. Young D, Morton R, Bartley J. Therapeutic ultrasound as treatment for chronic rhinosinusitis: preliminary observations. J Laryngol Otol 2010; 124:495-499. 